\title{
Optical Fiber Sensors to Detect Volatile Organic Compound in Sick Build- ing Syndrome Applications
}

\author{
Cesar Elosua ${ }^{*, 1}$, Candido Bariain ${ }^{2}$ and Ignacio Raul Matias ${ }^{3}$
}

\begin{abstract}
${ }^{I}$ Department of Electric and Electronic Engineering, Public University of Navarra, Edificio de los Tejos, Pamplona, Spain; ${ }^{2}$ Department of Electric and Electronic Engineering, Public University of Navarra, Edificio de los Tejos, Pamplona, Spain; ${ }^{3}$ Department of Electric and Electronic Engineering, Public University of Navarra, Edificio de los Tejos, Pamplona, Spain
\end{abstract}

\begin{abstract}
Health issues, such as Sick Building Syndrome (SBS), are being taken into account in new constructions, houses and several non industrial environments. SBS produces several manifestations, for example, respiratory irritative symptoms, headache and fatigue. It is caused by several factors. Most of them are related with the air quality, and the presence of Volatile Organic Compounds (VOCs), among other parameters. It is obvious that is very important to keep these parameters under control, and so, the development of new devices to achieve this is more and more interesting during last few years. Some important features using sensors for this application are robustness, easy installation, on line and real time use. Although there are electronic devices already available, optical fiber sensors offer all the performances mentioned before, as well as other ones exclusive of this technology: sensors networking and electromagnetic immunity mainly. In this work, we will show a review about the SBS aim, the sensing architectures of optical fiber technology, and the opportunities that it has in this increasing market niche.
\end{abstract}

\section{INTRODUCTION}

Health issues related to non industrial indoor environments are getting more importance due to their effect on humans. Poor ventilation combined with chemical pollutants can yield to a bad Indoor Air Quality (IAQ). This may even cause some health symptoms to people working or living inside the building; on the other hand, certain temperature and humidity conditions could also make easier the appearance of biological agents such as molds. These factors make easier the appearance of Sick Building Syndrome (SBS); this was first identified in the 1970s decade [1], and the World Health Organization defined it on 1983 [2] as non specific complaints, including upper - respiratory irritative symptoms, headache, fatigue, usually associated with a particular building by their temporal pattern of occurrence and clustering among inhabitants or colleagues. Volatile organic compounds (VOCs) are the main pollutants (which will be explain in detail later), and they have many potential sources. This way, it is very important to detect them and to know their concentrations. This makes necessary the use of sensors to handle with SBS: they have to alert when the IAQ is not satisfactory and when they detect the presence of biological agents as well.

There are electronic devices able to detect air pollutants, but in this context, optical fiber technologies offer some interesting features: real time and on line operation, light weight, electro magnetic immunity (office buildings are full of this type of noise), and the possibility of multiplexation (handle with several optical signals in just one optical cable),

*Address correspondence to this author at the Department of Electric and Electronic Engineering, Public University of Navarra, Edificio de los Tejos, Pamplona, Spain; Tel: +34 948 169328; Fax: +34 948 169720;

E-mail: cesar.elosua@unavarra.es just to mention a few. Regarding to biological agents detection, optical fiber is an inert substrate and needs no electrical signals to operate, so different enzymes can be fixed on it [3]. Thanks to these features, SBS applications are a potential market niche for optical fiber sensors.

In this article, we will start describing with more detail SBS, just to avoid confusions with other syndromes related with certain pathogen micro organism, specifying its main sources as well. After that, a brief description about optical technology will be shown. In the fourth section, we will introduce some concepts and classifications of optical fiber sensors that will help to follow the article; after this, different kind of sensors and topologies will be described, detailing in each case the potential use in SBS applications. Finally, we will remark the challenges that optical fiber sensors have in this context, with the newest advancements and the problems that have to overcome to have a successful implantation in this field.

\section{SICK BUILDING SYNDROME: A BRIEF DE- SCRIPTION}

SBS has to be distinguished from other well-known building-related illnesses caused by specific exposures in indoor environments [4]; some of these illnesses are rhinitis, asthma and pneumonitis (due to exposure to moulds, spores, or allergenic chemicals). Building outbreaks of infectious diseases (legionnaires, viral infections or tuberculosis) are well recognized [5]. A single exposure can result in more than one type of these responses. Typically in these disorders, evidence of clustering of cases in a small group (or host idiosyncrasy) provides clues to a specific building-related illness and a single causal factor. This is not the case of SBS: it can rarely be attributed to a single specific exposure.

First evidences about SBS were detected in 1970s, as a result of reducing fresh air supply and poor performance of 
the HVAC system. There are other factors that contribute to the SBS: synthetic materials widely in building construction, a higher number of workers in office, the use of personal computers drying the air and cleaning or perfuming products, just to mention a few. This way, the cause of SBS can not be established with a single or even a group of environmental factors [6]. One of the most popular theories for some years was that the main SBS source was the effect of several VOCs present at low concentrations that, all together, produce a toxic effect. Recently, other factors related with biological contaminants and psychosocial matters are considered as direct sources of SBS [7]. In Table 1, a brief list of the main factors that are related with SBS is shown. Anyway, many factors affect this syndrome, and the presence of VOCs is taken into account in all theories, so its detection and control are very important to handle with the SBS.

Table 1. Main Environmental Factors Related to SBS

\begin{tabular}{|c|c|}
\hline \multicolumn{2}{|c|}{ Most Important Factors Related with SBS } \\
\hline VOCs & $\begin{array}{c}\text { Formaldehyde } \\
\text { Solvents } \\
\text { Paints and resins }\end{array}$ \\
\hline Dust & $\begin{array}{c}\text { Dirt } \\
\text { Construction } \\
\text { Paper dust }\end{array}$ \\
\hline Biological Agents & $\begin{array}{c}\text { Bacteria } \\
\text { Fungis } \\
\text { Pollen } \\
\text { Viruses }\end{array}$ \\
\hline OutDoor Agents & $\begin{array}{l}\text { Vehicle exhaust } \\
\text { Industrial exhaust }\end{array}$ \\
\hline Human Activity & $\begin{array}{c}\text { Carbon dioxide } \\
\text { Perfume }\end{array}$ \\
\hline Physical Factors & $\begin{array}{c}\text { Temperature } \\
\text { Humidity }\end{array}$ \\
\hline
\end{tabular}

\section{OPTICAL FIBER SENSORS TECHNOLOGY}

Our purpose is not to provide a detail explanation about this field, just a few concepts that will help us to link it with the SBS application needs. It is well known that optical fiber and photonic technologies introduced a great advance in communication systems: the main reasons were, among others, low attenuation of optical signals and a higher capability to transfer information compared with electronic communications along greater distances. The reader can find a detailed explanation about this in [8]. With the optimal results obtained in this field, it was thought that this technology could be also incorporated to other areas, for example, sensing devices and systems. Compared to other solutions available, optical fiber is a passive substrate that does not need any electrical signal to operate, just light: this is a great feature in environments where there is an explosion risk be- cause of the presence of some gases [9]; they can be used in places with high levels of electromagnetic noise, as the fiber is a dielectric material [10]; another good feature is the possibility of integrate several sensors in one network, even each one can detect different parameters (multiplexation capability). Of course, there are some drawbacks: photonic devices are still more expensive than electronic ones, and this second technology is much more mature. Nowadays, there are electronic sensors for almost all applications, and they are cheaper and easy to obtain than optical fiber ones; but there are some market niches were these sensors are widely used thanks the properties mentioned above. So, this technology has to find the specific applications where it offers features that electronic devices does not, as is pointed in several optical fiber sensors reviews [11-13]. One of this fields, is the detection of VOCs and gases [14], and so, the prevention of SBS.

\section{SENSOR CONFIGURATION \& VOCS DETECTION}

These devices work with optical signals, this is light, and as sensors, there must be an interaction (transduction) between the light that travels through the fiber and the parameter to detect, in our case, different VOCs and gases. There are some criteria to classify this kind of sensors, for example, the change that light signal suffers: it can be measured in terms of power, frequency or phase (modulation). Another option is related with the place where the transduction occurs, this is, inside or outside the fiber, dividing the sensors in two groups: intrinsic and extrinsic [15].

\subsection{Extrinsic Sensors}

In this case, the fiber just guides the light to an area where the measurement takes place, and couples this signal once it has been modulated by the VOC or gas (fig. 1). It is important to note that this solution has been used in real applications [16]: the sensing system only needs to install the fiber, and it is not necessary any treatment to make it sensitive to the gas to detect. This sensing architecture is related to spectrography: the wavelength (frequency) of light that travels through the fiber matches one spectral absorption line of the gas to detect. In Table 2 there are shown the absorption lines gases of interest $\left(\mathrm{CO}, \mathrm{CO}_{2}, \mathrm{O}_{2}, \mathrm{NH}_{3}, \mathrm{CH}_{4}\right)$.

With this scheme, very selective sensors can be obtained, and with just one light source and one receptor, a multipoint sensor network can be implemented, for example, in a building. Typically, the optical fibers are placed one opposite the other, so they have to be accurately aligned; looking for this, micro cells are used to connect the fibers and avoid noise due to a bad alignment. Other gases can interfere the measure, but it can be overcome making the input signal more robust using modulations [17].

Depending on the final application, it might be interesting the use of a multi point sensor network able to detect several gases (Fig. 2), no just one, as mention above. It can be done with the same configuration, and only the optical source has to be changed to achieve this. The idea is that, along time, the optical source tunes the wavelength of the light emitted, matching it with the absorption line of different gases. This is known as Wave Spectral Modulation (WSM) [18]. 

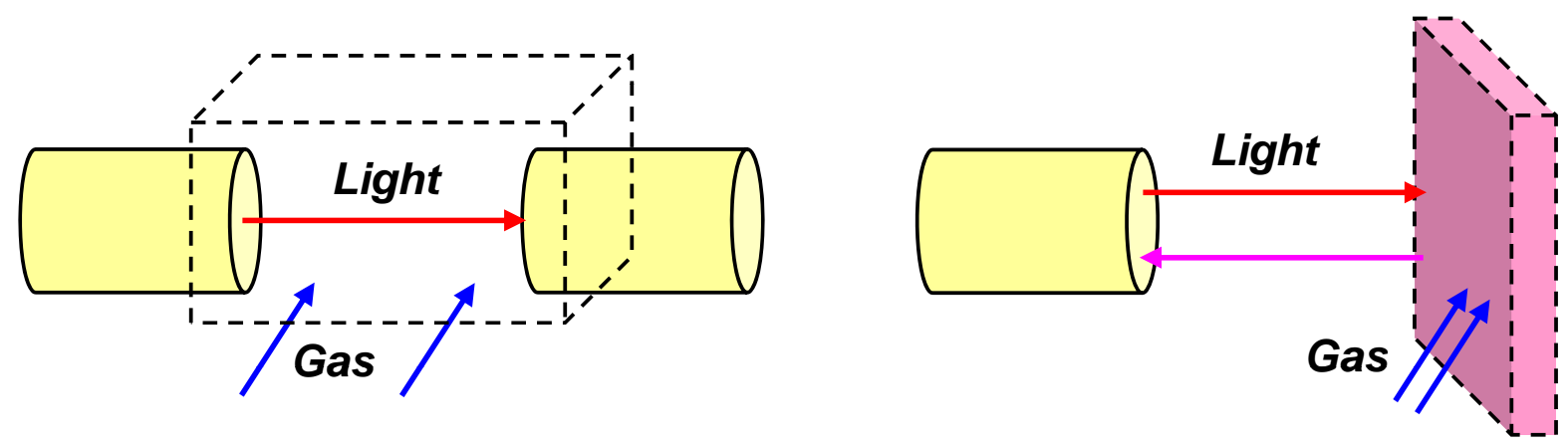

Fig. (1). Typical configurations for extrinsic sensors: fibers embedded in a microcell where air flows (left) and light guided and coupled from a sensing substrate.

Another possibility for extrinsic sensors is that change of the light can be accomplished by a chemical agent. This way, a substrate, with a dye sensitive to the target gas, is placed in the optical path of the light. The optical properties of this obstacle are modified in presence of the gas or vapor, and so, the light that passes through it [19] (or that is reflected [20]), suffers a detectable change. Using different dyes, different gases can be detected, and so, this solution allows to design a network with sensors able to handle with several targets.

Table 2. Gases Related with SBS with their Spectral Absorption Lines and Strengths

\begin{tabular}{|c|c|c|}
\hline Gas & $\begin{array}{c}\text { Absorption Line } \\
(\mathbf{n m})\end{array}$ & $\begin{array}{c}\text { Line Strength } \\
\left(\mathbf{c m}^{-\mathbf{2}} \mathbf{a t m}^{-\mathbf{1}} \mathbf{1 0}^{-\mathbf{2}}\right)\end{array}$ \\
\hline \hline $\mathrm{NH}_{3}$ & 1544 & 0.925 \\
\hline $\mathrm{CO}$ & 1567 & 0.0575 \\
\hline $\mathrm{CO}_{2}$ & 1573 & 0.04 \\
\hline $\mathrm{CH}_{4}$ & 1667 & 1.5 \\
\hline $\mathrm{H}_{2} \mathrm{O}$ & 1365 & 52.5 \\
\hline $\mathrm{O}_{2}$ & 761 & 0.019 \\
\hline $\mathrm{NO}_{2}$ & 800 & 0.125 \\
\hline
\end{tabular}

\subsection{Intrinsic Sensors}

As it was said before, in this type of sensors the optical fiber plays a more active role, as the transduction between the target and the light takes place in or on it. In most cases, a chemical layer is fixed onto the fiber, affecting the way light travels through it, although there are some examples where the fiber itself acts as the sensitive material, as will be shown later. Finally, the chemical dye can emit an optical signal depending on the surrounding environment, and hence, use this to detect VOCs or gases.

\subsubsection{Evanescent Wave Sensors}

This was the sensor configuration most studied along the 1990s [21]. In most of them, a segment of the fiber acts as sensing area (avoiding open paths, as in extrinsic sensors). Optical fibers have a cladding around a core, and its properties affect the light transmitted along the fiber. The passive cladding of the optical fiber can be replaced along a small section, by a sensitive material, so these sensors are also known as transmissive; this way, any change in the optical characteristics of the dye will alter the transmission of the light [22]. The sensitivity depends on several parameters, mainly both the chemical properties of the dye and the light propagation; this last one can be studied by Beer-Lambert law [23] and ray theory approximation [24, 25] (Fig. 3).

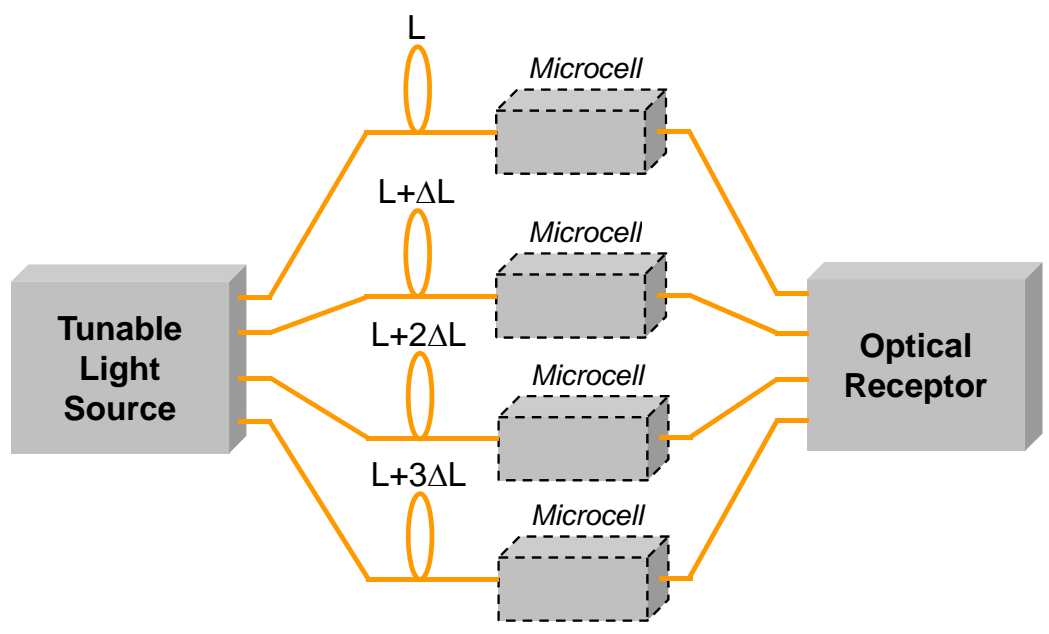

Fig. (2). An extrinsic sensors network: each device has a path with a different length, so the signals reaches the receptor at different times, and so, can be measured individually. 


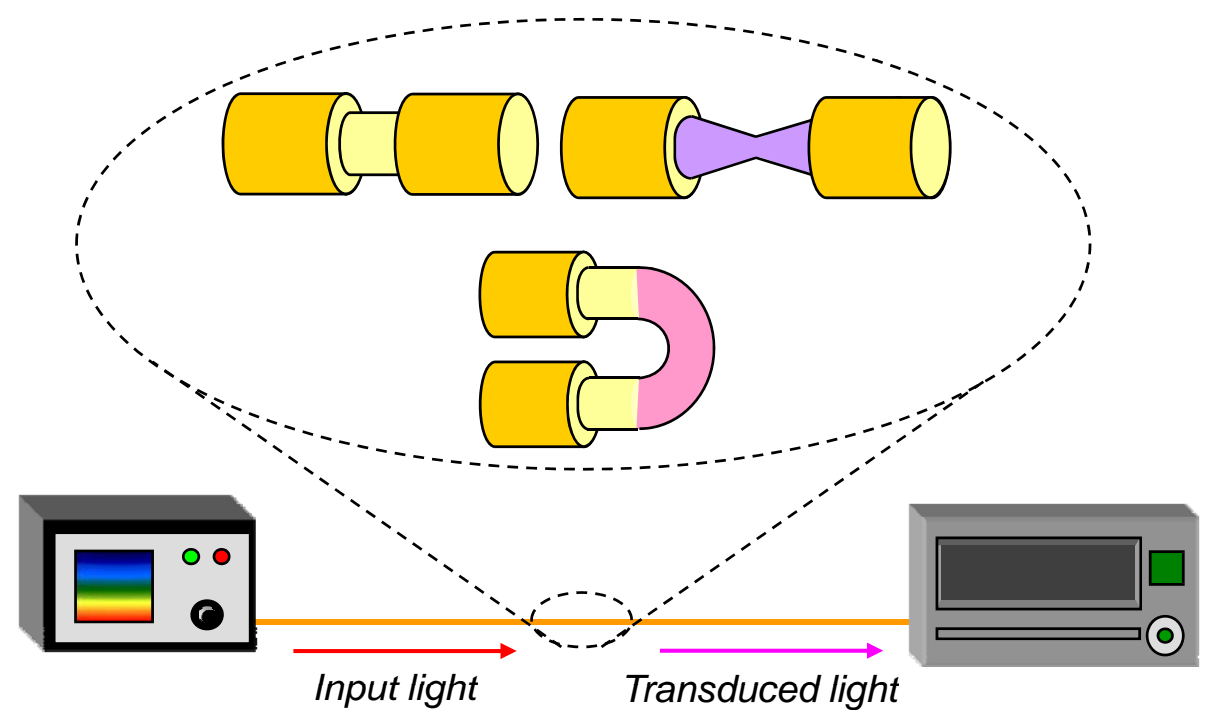

Fig. (3). Experimental set up for an evanescent wave sensor, with three different possibilities: removing the cladding (top-left), tapering the fiber (top-right) and bending the fiber (down-center).

One of the main problems of these sensors (and all the sensors that need a chemical dye), is fixing the sensing material onto the fiber. In many cases, it is in solid state and has to be solved and then deposited. The implementation of the sensor involves several steps: removing the cladding, solving the material and fixing it; obviously, this process has to be repetitive and seems to be worst than the one with extrinsic sensors. On the other hand, chemical dyes offer an almost unlimited number possibilities of detection of different VOCs or gases, and among other features, this justify the whole implementation process.

There are some chemical processes used to fix the sensing material; one of the most popular is dipping the fiber into a sol gel [26]. This is a mixture made of silica, the same material as optical fiber. The sensing material is added to the sol-gel solution while it is still in liquid phase, dipping the fiber into the mixture. After drying the deposition, an optically uniform porous matrix doped with the analyte is obtained. Recently, efforts have been focused on controlling the size of the porous once the sol-gel is deposited: this can give an additional sensing mechanism based on discrimination between organic vapor molecules depending on their molecular size. Sol-gel solutions deposited with dip coating technique are a typical combination used in recent years to implement evanescent wave sensors [27]. Other important deposition techniques are Langmuir-Blodgett [28] and the Electrostatic Self-Assembly method (ESAm). Many research is being pointed to this last technique as it allows to fix nano metric layers onto substrates independently of its surface shape, which is a great feature when implementing optical fiber sensors [29].

Talking about the sensing materials, there are several families sensitive to different organic solvents, having a reversible reaction in presence of different VOCs, which is transduced into a change of the optical light propagated in the fiber. Some examples are the Vapochromic complexes [30] (which suffer a color change), polyaniline, hydrophilic films [31] (ideal to monitorize humidity levels), and certain polymers. New sensors based on these materials are described in recent studies $[32,33]$, and offer interesting potential uses. The only limitation of these materials is that they need to react with the target, so it is very difficult to synthesize one able to detect inert gases such as $\mathrm{CO}_{2}$ or $\mathrm{CO}$, very important in IAQ.

This kind of sensors has sometimes a low sensitivity due to the limited effect of the modified cladding on the transmitted light. Some approaches have been studied so far to overcome this problem. The fiber can be bent enhancing the interaction between the light and the cladding [34]. Dimensions of standard fiber are $125 \mu \mathrm{m}$, and after the bending process, it might become weak, so in these cases, the employed fibers have core diameters up to $1 \mathrm{~mm}$ to avoid crushing. It is also possible to coil a few meters of an optical fiber with modified cladding [35]. Another extended solution is based on tapering the fiber [32], increasing a lot the interaction between the light and the chemical dye; in this case, as the fiber is stretched, it is weaker, so this should be only used in applications where the sensor is not exposed to high mechanical efforts. Finally, the sensitivity can be also increased taking advantage of the fact that the light travels through the core of the optical fiber: it consists on synthesizing a segment of optical fiber from a sol gel solution, so it can be doped with the desired sensing material [36]; after it is dried, it can be fused to standard fibers. This is known as active fiber core sensors. The main drawback of this solution is the aging effect, which is more critical than in evanescent wave sensors.

\subsubsection{Reflection Sensors}

Inside the intrinsic configurations category, reflection sensors consist of an end-cut optical pigtail, onto which a chemical dye is deposited. As can be seen in Fig. (4), the light is coupled from the source and is guided until the sensor head, where the light interacts with the sensing deposition. Depending on the optical properties of this layer, a part of the light will go through this interface, and another part 


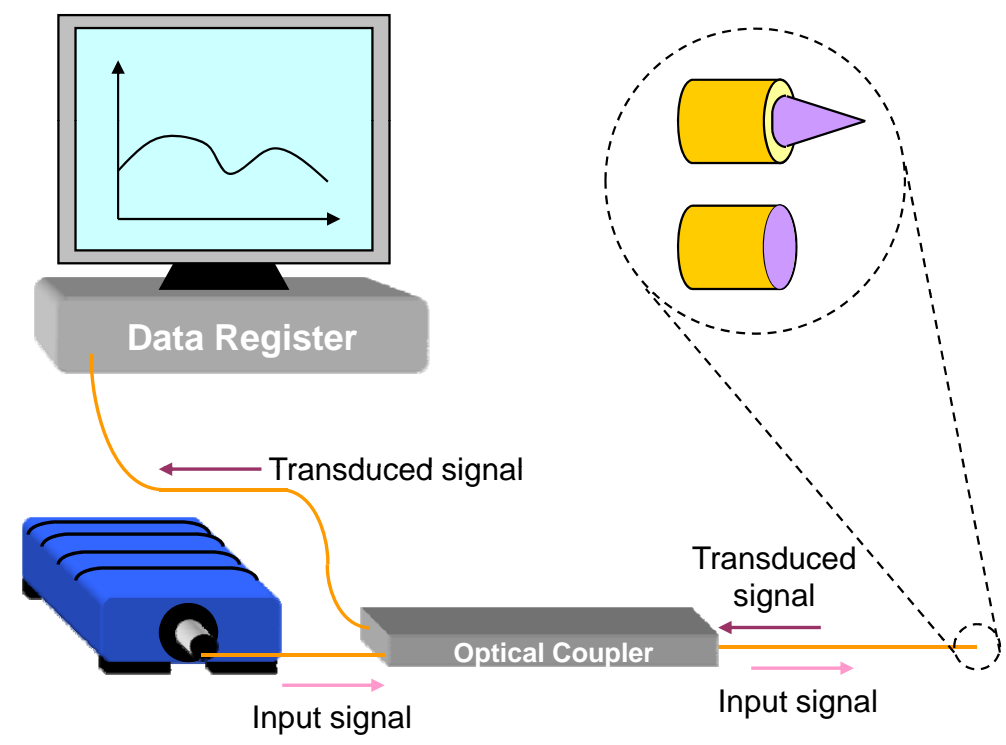

Fig. (4). Experimental reflective set - up. Two possible sensor heads are shown: a perpendicular ending (which maximizes the reflected optical power), and a tapered one (used when the fluorescence of the chemical dye has to be coupled into the fiber).

will be reflected back. This process is governed by the Fresnel's law, and is described in detail in [37]. An optical coupler is needed to guide the reflected signal, and is the main device of this configuration.

The sensor head employed in this configuration is used in the same way as chemical electrodes, and so, this type of sensors are also called optrodes. This makes the sensor small and easy to place, and as no cladding has to be removed, they are more robust than transmissive sensors. The transduction takes place only in the core section of the fiber, which is a significantly smaller area than in evanescent wave sensors; besides, reflected optical power is, in the best case, around $4 \%$ of the incident signal on the interface. In spite these drawbacks, its small size and high robustness justify the use of these sensors.
Regarding to the selectivity, it is similar than with transmissive sensors: it depends mainly on the chemical dye fixed onto the fiber (Fig. 5). The techniques used to fix the sensing material are similar than the ones used in evanescent wave sensors; among all of them, ESAm is offering the best results in terms of reproducibility, thanks to the fact that it is an iterative process [38]. In order to obtain the maximum reflected power, the end of the pig tail has to be as perpendicular as possible. The sensitivity depends a lot on the chemical dye as well.

There are other sensing mechanisms typical of this configuration, apart of the measuring just the reflected optical power. Recently, new plastic cladding fibers (PCFs) with wider dimensions (from 220 to $1000 \mu \mathrm{m}$ ) are used to increase the sensitivity [39]. Using them, the chemical dye can be illuminated with a white light signal, and so, its color is re-

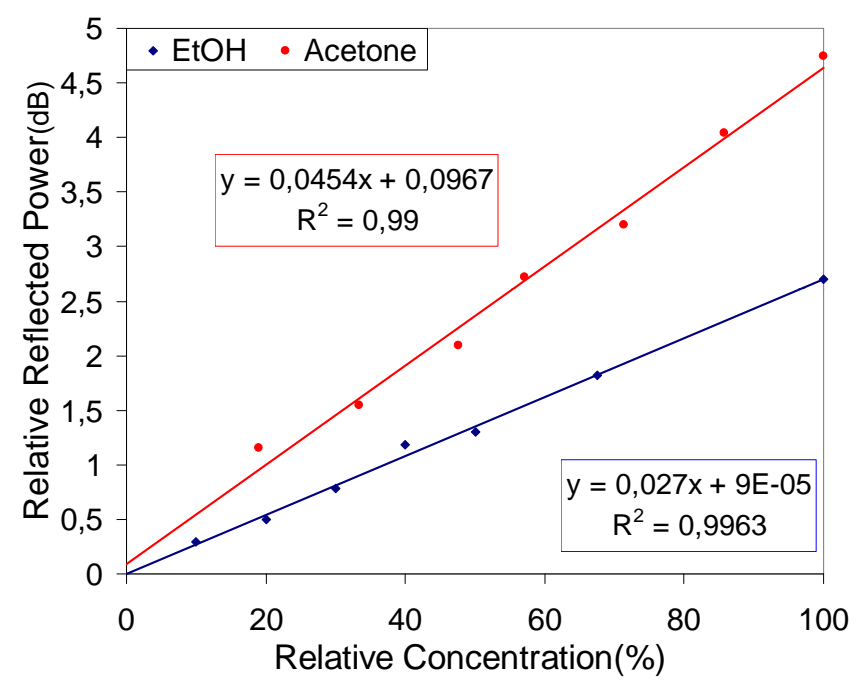

Fig. (5). Linear approximations between reflected optical power and relative concentration, from a sensor exposed to two different VOCs. 


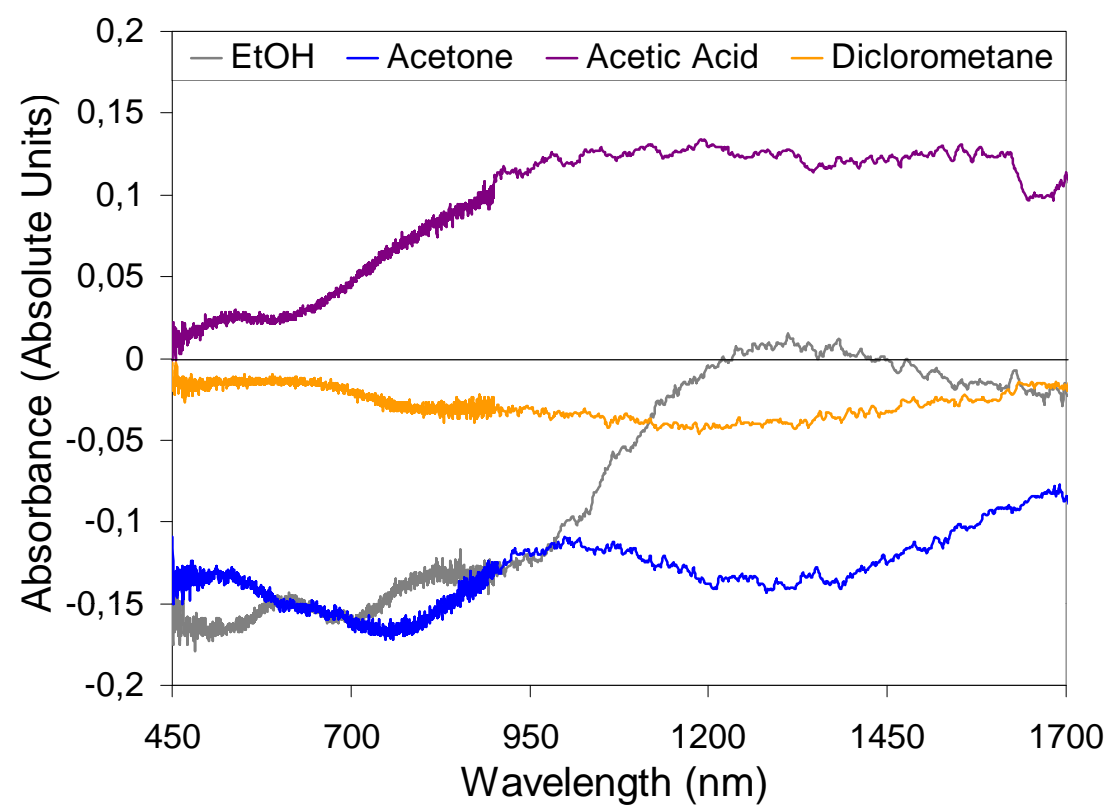

Fig. (6). Time response for a sensor when exposed to 3 different VOCs; the can be differentiated in terms of variation in reflected optical power or recovery time.

flected to the detector (Fig. 6): as mentioned before, there are some vapochromic complexes that suffer color changes in presence of so VOCs, so this transduction can be used to detect them. Another important mechanism is based on the spontaneous light emission of the chemical dye when it is excited with light at a certain wavelength. In other words, the sensing material shows a fluorescence emission, and it is altered by the target gas in terms of amplitude or color. One of the most studied materials is ruthenium, and it has been successfully used to determinate the $\mathrm{O}_{2}$ concentration [40], which is a very important parameter is AIQ, and so, in SBS applications. Looking for to maximize the fluorescence coupled to the fiber, some special terminations are built onto the cut-end pigtails, usually tapers [41].

\subsection{Hybrid Sensors}

This configuration comes from the combination of the ones described before. There are many possibilities to use together sensing mechanism of reflective and evanescent wave sensors. For example, by modifying the cladding of an optical mirror-ended pigtail, it is guaranteed that the optical power is modulated twice: first, when the light passes through the sensing area to the end, and then, when the signal travels back from the mirror to the detector, passing again through the modified cladding area [42]. It is also possible to use a bent evanescent wave mirror-ended sensor. Another choice consists on using an active core fiber with a reflection scheme; the effect on the transmitted light is added to effect on the interface between the fiber and the air.

\section{CHALLENGES AND OPPORTUNITIES OF OPTI- CAL FIBER SENSORS IN SBS APPLICATIONS}

So far, a brief description of different sensing approximations has been exposed. With this global point of view, now we can see the advantages and potential applications that this kind of sensors offers in SBS field. The main drawback is that electronic sensors are more mature and that technology is cheaper compared to the optical fiber one, although the prices of optical devices are getting cheaper along last decades. Anyway, one of the most important advantages that optical fiber sensors offer is the possibility of multiplexation. In Fig. (7), the absorbance spectra of a sensor is shown: there is a wide spectral range where the sensor can operate, and so, be multiplexed with other sensors. There are proposed several networks to handle with sensors [43], and this is very interesting when thinking about installing them in a building. All of them could be controlled on line and real time in parallel, so if one doesn't work properly, it wouldn't affect the rest of the network. Besides, this network are transparent to the sensors, this means that devices sensitive to different VOCs can be included in the same network. This is a clear advantage compared to other solutions such as hand held devices [44]. Beyond the possibility of implementing a multi sensor network, new techniques allows to determine the temperature along a fiber network with a spatial accuracy around $35 \mathrm{~cm}$ [45], which, although does not have nothing to do with VOCs or gas detection, is very attractive to SBS applications. This sensing capability can be used superposed to the network, so it would not interfere with the sensors responses. This is a very interesting potential application.

In case of gas detection, WSM techniques described in extrinsic sensors section are the best to detect low reactivity gases, as they show a high selectivity and the use of certain modulations minimizes the effect of other interfering gases. This is a good way to register the concentration of $\mathrm{CO}_{2}$ and $\mathrm{CO}$, and so, control the ventilation and IAQ. Humidity and $\mathrm{O}_{2}$ might be also detected by WSM, but better results are obtained with intrinsic sensors combined with chemical dyes. This is the same case with VOCs. Sensing materials offer the possibility to detect a VOC if it interacts with the sensing layer, and it most of cases, the change is reversible. At this point, these materials show a lower selectivity com- 


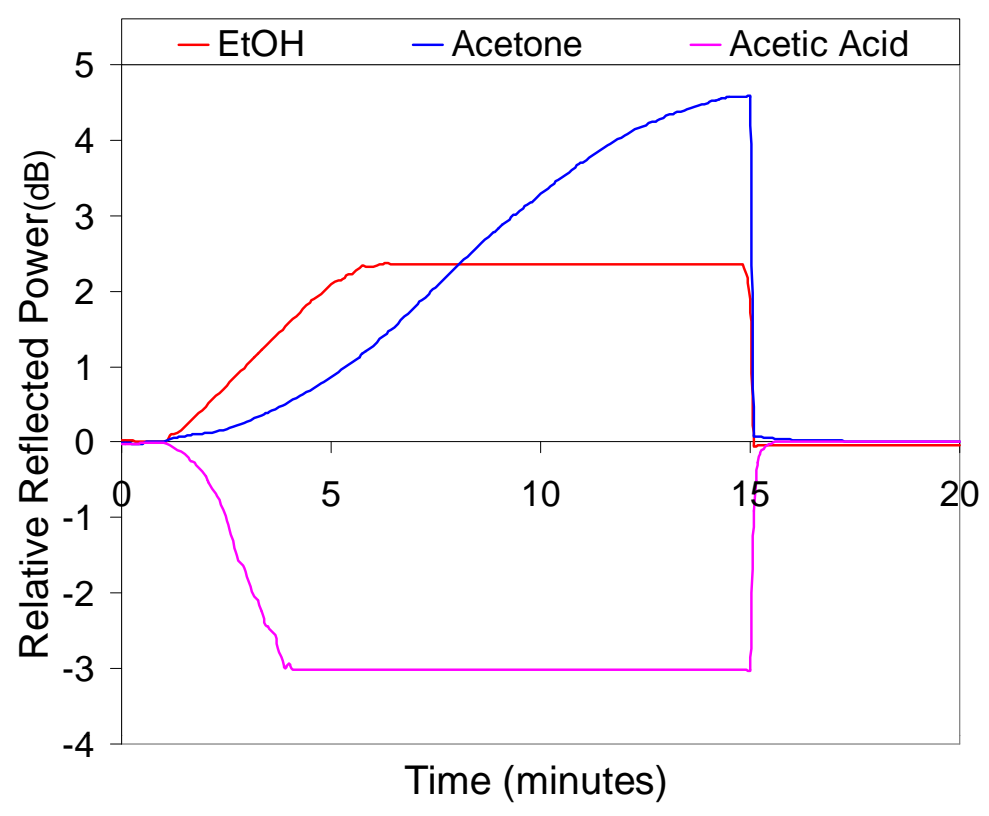

Fig. (7). Absorbance spectra obtained from a single sensor.

pared with WSM, as they usually react with a family for VOCs, for example, alcohols, formaldehydes or ammonia complexes. So, it is difficult that a sensor could react to a certain alcohol, for example ethanol, and not to another one, such as methanol (Fig. 7). However, it could show a significant response to alcohols and a neglible one to other VOCs. This way, another sensor could react to, for example, formaldehydes, and register a little response to alcohols. As SBS is not affected by a single VOC, several sensors with different selectivities can be combined to obtain fingertips to identify global VOCs mixtures that could yield to SBS. Anyway, there are some cases where toxic vapors can be detected with a low interference from other vapors, which the case of $\mathrm{NO}_{2}$ [46], $\mathrm{CHCl}_{3}$ [37] and $\mathrm{NH}_{3}$ [47].

\section{CONCLUSIONS}

SBS is a health issue that has to be taken into account both in work and house buildings. It is due not only to a single factor, but to a global effect of physical conditions, air quality, chemical pollutants and biological agents. Optical fiber sensors is an emerging technology that offer attractive issues to detect one of the factors involved in SBS, which is the quality of air, mainly, the presence of VOCs and different gases levels $\left(\mathrm{O}_{2}, \mathrm{CO}_{2}, \mathrm{CO}, \mathrm{NO}_{2}\right)$. An overview about the main sensing configurations has been shown, pointing the main drawbacks and advantages for each case. Just to remind them briefly, these sensors show electromagnetic immunity (useful in environments where electric and or electronic devices are used), are light weighted, their size is small and sensors network can be implemented thanks to their multiplexation capability. On the other hand, this technology is not so developed as the electronic one, making electronic devices cheaper. Though electronic sensors have been used since years ago, and so, the technology is more mature and more accessible, optical fiber sensors offer some interesting capabilities that make them a potential alternative in the next years in certain markets niche as SBS applications.

\section{ACKNOWLEDGEMENTS}

Financial support from the Spanish Comisión Interministerial de Ciencia y Tecnología within projects TEC2007-67987-C02-02 and TEC2007-68065-C03-01, and FEDER funds is acknowledged.

\section{REFERENCES}

[1] D. Menzies, and J. Bourbeau, "Building-related illnesses", The New England Journal of Medicine, vol. 337, pp. 1524-1531, 1997.

[2] A. Thron, "The sick building syndrome: a diagnostic dilemma", Social Science Medicine, vol. 47(9), pp. 1307-1312, 1998.

[3] J. M. Corres, A. Sanz, F. J. Arregui, I. R. Matías, and J. Roca, "Fiber optic glucose sensor based on bionanofilms", Sensors and Actuators B, vol. 131, pp. 633-639, 2008.

[4] "Occupational Safety, and Health Administration. Indoor air quality, 29 CFR", Fed Register, 1994, pp. 15968-6039.

[5] T. Husman, "Health effects of indoor-air microorganisms", Scandinavian Journal of Work, Enrionmental \& Health, vol. 22, pp. 5-13, 1996.

[6] M. J. Mendell, "Non-specific symptoms in office workers: a review and summary of the literature", Indoor Air, vol. 3(4), pp. 227-236, 1993.

[7] H. L. M. Hodgson, and P. Wolkoff, "Volatile organic compounds and indoor air", Journal of Allergy \& Clinical Immunology, vol. 94 pp. 296-304, 1994.

[8] G. P. Agrawal, Fiber-Optic Communication Systems: John Wiley \& Sons, Inc., New York, 2002.

[9] H. Thomas, and J. Dubaniewicz, "Methane-air mixtures ignited by CW laser-heated targets on optical fiber tips: Comparison of targets, optical fibers, and ignition delays", Journal of Loss Prevention in the Process Industries, vol. 19, pp. 425-432, 2006.

[10] K. Bohnert, P. Gabus, J. Kostovic, and H. Brändle, "Optical fiber sensors for the electric power industry", Optics and Lasers in Engineering, vol. 43, pp. 511-526, 2005.

[11] B. Lee, "Review of the present status of optical fiber sensors", Optical Fiber Technology, vol. 9, pp. 57-79, 2003.

[12] C. K. Y. Leung, "Fiber optic sensors in concrete: the future?", NDT\&E International, vol. 34, pp. 85-94, 2001.

[13] K. Hotate, "Fiber sensor technology today", The Japan Society of Applied Physics, vol. 45 (8B), pp. 6616-6625, 2006.

[14] C. Elosua, I. R. Matias, C. Bariain, and F. J. Arregui, "Volatile organic compound optical fiber sensors: a review”, Sensors, vol. 6, pp. 1440-1465, 2006. 
[15] I. R. Matias, F. J. Arregui, and R. O. Claus, Fiber Optics Hand Book: Fiber, Devices and Systems for Optical Communications. Ch. 15. $1^{\text {st }}$ ed. McGraw Hill Professional, New York, 2001, vol. 1.

[16] B. Culshaw, G. Stewart, F. Dong, C. Tandy, and D. Moodie, "Fibre optic techniques for remote spectroscopic methane detection-from concept to system realisation", Sensors and Actuators B, vol. 51, pp. 25-37, 1998.

[17] C. T. G. Stewart, D. Moodie, M. A. Morante, and F. Dong, "Design of a fibre optic multi-point sensor for gas detection", Sensors and Actuators B, vol. 51, pp. 227-232, 1998 .

[18] G. Whitenett, G. Stewart, K. Atherton, B. Culshaw, and W. Johnstone, "Optical fibre instrumentation for environmental monitoring applications", Journal of optics A: Pure and Applied Optics, vol. 5, pp. 140-145, 2003.

[19] S. Christie, E. Scorsone, K. Persaud, and F. Kvasnik, "Remote detection of gaseous ammonia using the near infrared transmission properties of polyaniline", Sensors and Actuators B, vol. 90, pp. 163-169, 2003.

[20] B. Kondratowicz, R. Narayanaswamy, and K. C. Persaud, "An investigation into the use of electrochromic polymers in optical fibre gas sensors", Sensors and Actuators B, vol. 74, pp. 138-144, 2001.

[21] S. K. Khijwania, and B. D. Gupta, "Fiber optic evanescent field absorption sensor with high sensitivity and linear dynamic range", Optics Communications, vol. 152, pp. 259-262, 1998.

[22] S. Khalil, L. Bansal, and M. El-Sherif, "Intrinsic fiber optic chemical sensor for the detection of dimethyl methylphosphonate", Optical Engeeniring, vol. 43(11), pp. 2683-2688, 2004.

[23] T. A. Dickinson, K. L. Michael, J. S. Kauer, and D. R. Walt, "Convergent, self-encoded bead sensor arrays in the design of an artificial nose", Analytical Chemistry, vol. 71, pp. 2192-2198, 1999.

[24] J. Yuan, and M. A. El-Sherif, "Fiber-optic chemical sensor using polyaniline as modified cladding material", IEEE Sensors Journal, vol. 3(1), pp. 5-12, 2003.

[25] A. Messica, A. Greenstein, and A. Katzir, "Theory of fiber-optic, evanescent-wave spectroscopy and sensors", Applied Optics, vol. 35(13), pp. 2274-2284, 1996

[26] S. Sekimoto, H. Nakagawa, S. Okazaki, K. Fukuda, S. Asakura, T. Shigemori, and S. Takahashi, "A fiber-optic evanescent-wave hydrogen gas sensor using palladium-supported tungsten oxide", Sensors and Actuators B, vol. 2000, pp. 142-145, 2000.

[27] M. Bezunartea, J. Estella, J. C. Echeverría, C. Elosúa, C. Bariáin, M. Laguna, A. Luquin, and J. J. Garrido, "Optical fibre sensing element based on xerogel-supported [Au2Ag2(C6F5)4(C14H10)]n for the detection of methanol and ethanol in the vapour phase", Sensors and Actuators B, vol. 134, pp. 966-973, 2008.

[28] W. Hu, Y. Liu, Y. Xu, S. Liu, S. Zhou, D. Zhu, B. Xu, C. Bai, and C. Wang, "The gas sensitivity of Langmuir-Blodgett films of a new asymmetrically substituted phthalocyanine", Sensors and Actuators B, vol. 56, pp. 228-233, 1999.

[29] F. J. Arregui, I. R. Matías, and R. O. Claus, "Optical fiber gas sensors based on hydrophobic alumina thin films formed by the electrostatic self-assembly monolayer process", IEEE Sensors Journal, vol. 3(1), pp. 56-61, 2003.

[30] A. Luquin, C. Bariain, E. Vergara, E. Cerrada, J. Garrido, I. R. Matias, and M. Laguna, "New preparation of gold-silver complexes and optical fibre environmental sensors based on vapochromic [Au2Ag2(C6F5)4(phen)2]n", Applied Organometallic Chemistry, vol. 19, pp. 1232-1238, 2005 .
[31] C. Bariain, I. R. Matıas, F. J. Arregui, and M. López-Amo, "Optical fiber humidity sensor based on a tapered fiber coated with agarose gel", Sensors and Actuators B, vol. 69, pp. 127-131, 2000

[32] C. Bariain, I. R. Matıas, I. Romeo, J. Garrido, and M. Laguna, "Detection of volatile organic compound vapors by using a vapochromic material on a tapered optical fiber", Applied Physics Letters, vol. 77(15), pp. 2274-2276, 2000

[33] C. Elosua, C. Bariain, I. R. Matias, F. J. Arregui, E. Vergara, and M. Laguna, "Optical fiber sensing devices based on organic vapor indicators towards sensor array implementation", Sensors and Actuators B, vol. 137, pp. 139-146, 2009.

[34] S. A. Grant, J. H. Jr. Stacher and K. Bettencourt, "Development of sol-gel-based fiber optic nitrogen dioxide gas sensors", Sensors and Actuators B, vol. 69, pp. 132-137, 2000.

[35] E. Scorsone, S. Christie, K. C. Persaud, and F. Kvasnik, "Evanescent sensing of alkaline and acidic vapours using a plastic clad silica fibre doped with poly(o-methoxyaniline)", Sensors and Actuators B, vol. 97, pp. 174-181, 2004.

[36] R. Falate, R. C. Kamikawachi, M. Muller, H. J. Kalinowski, and J. L. Fabris, "Fiber optic sensors for hydrocarbon detection", Sensors and Actuators B, vol. 105, pp. 430-436, 2005.

[37] M. Giordano, M. Russo, A. Cusano, and G. Mensitieri, "An high sensitivity optical sensor for chloroform vapours detection based on nanometric film of $\delta$-form syndiotactic polystyrene", Sensors and Actuators B, vol. 107,pp. 140-147, 2005.

[38] C. Elosua, C. Bariain, I. R. Matıas, F. J. Arregui, A. Luquin, and M. Laguna, "Volatile alcoholic compounds fibre optic nanosensor", Sensors and Actuators B, vol. 115, pp. 444-449, 2006.

[39] S. Casado-Terrones, C. Elosua, C. Bariain, and A. S. Carretero, "Volatile-organic-compound optic fiber sensor using a gold-silver vapochromic complex", Optical Engeeniring, vol. 45(4), pp. 044401-0444017, 2006

[40] B. K. Otto, S. Wolfbeis, K. Goswami, and S. M. Klainer, "Fiberoptic fluorescence carbon dioxide sensor for environmental monitoring", Mikrochimica Acta, vol. 129, pp. 181-188, 1998.

[41] P. C. P. A. S. Jorge, C. C. Rosa, A. G. Oliva, and J. L. Santos, "Optical fiber probes for fluorescence based oxygen sensing", Sensors and Actuators B, vol. 103, pp. 290-299, 2004.

[42] P. S. Grant, and M. J. McShane, "Development of multilayer fluorescent thin film chemical sensors using electrostatic selfassembly", IEEE Sensors Journal, vol. 3(2), pp. 139-146, 2003

[43] R. A. Pérez-Herrera, M. A. Quintela, M. Fernández-Vallejo, A. Quintela, M. Lopez-Amo, and J. M. Lopez-Higuera, "Stability comparison of two ring resonator structures for multiwavelength fiber lasers using highly doped Er-fibers", Journal of Lightwave Technology, 2009, In press.

[44] K. Kawamura, K. Kerman, M. Fujihara N. Nagatania, T. Hashiba, and E. Tamiya, "Development of a novel hand-held formaldehyde gas sensor for the rapid detection of sick building syndrome", Sensors and Actuators B, vol. 105, pp. 495-501, 2005.

[45] S. Diaz, S. F. Mafang, M. Lopez-Amo, and L. Thevenaz, "A highperformance optical time-domain brillouin distributed fiber sensor", IEEE Photonic Technology Letters, vol. 8(7), pp. 1268-1272, 2008.

[46] S. J. Mechery, and J. P. Singh, "Fiber optic based gas sensor with nanoporous structure for the selective detection of $\mathrm{NO} 2$ in air samples", Analytica Chimica Acta, vol. 557, pp. 123-129, 2006.

[47] D. Galbarra, F. J. Arregui, I. R. Matias, and R. O. Claus, "Ammonia optical fiber sensor based on self-assembled zirconia thin films", Smart Materials and Structures, vol. 15, pp. 739-744, 2005.

(c) Elosua et al.; Licensee Bentham Open.

This is an open access article licensed under the terms of the Creative Commons Attribution Non-Commercial License (http://creativecommons.org/licenses/by-nc/3.0/) which permits unrestricted, non-commercial use, distribution and reproduction in any medium, provided the work is properly cited. 